\title{
Brecha laboral por motivos de género: diagnóstico y desafíos
}

Matías Poltorak|Universidad de Buenos Aires

Revista Derechos en Acción

Año 3/NNo 9 Primavera 2018, 505-524

DOl: https://doi.org/10.24215/25251678e238

ORCID: https://orcid.org/0000-0001-5670-9543

\section{Introducción}

Sangre mía, de alba, de luna partida, del silencio

Los versos que encabezan esta introducción corresponden a un extracto del poema "Sangre nuestra" de la mexicana Susana Chávez en homenaje a las mujeres víctimas de femicidios. La poeta era oriunda de Ciudad Juárez y fue una voz activa contra la violencia hacia las mujeres y los homicidios por motivo de género. En el 2011, con sólo treinta y seis años de edad, fue asesinada luego de ser violada y mutilada. En 1995, Susana acuñó la frase "ni una muerta más" para denunciar lo que ocurría en su pueblo natal.

Esa expresión inspiró a un colectivo de mujeres en Argentina para organizar la marcha "Ni una menos" el 3 de junio de 2015 luego del femicidio de Chiara Pérez, una adolescente de catorce años. Esa movilización multitudinaria fue un momento bisagra en la sociedad y tuvo un efecto multiplicador en numerosas partes del mundo. Ese día se expuso una penosa realidad: a las mujeres las mataban por ser mujeres. Esa primera convocatoria buscó con éxito poner en evidencia esa situación. Las cifras (que no son meros números, sino que detrás de ellos 
había personas con sus historias, anécdotas, sueños, ilusiones, proyectos que fueron interrumpidos y arrebatados por odio de género) acompañaban la necesidad de hacer oír su voz: en ese año hubo doscientas ochenta y seis víctimas de femicidios.

Los asesinatos y ataques contra la integridad sexual de las mujeres constituyen la muestra más extrema y cruda de la violencia de género, pero son parte de una larga cadena en la cual esa violencia está anclada, instalada e institucionalizada. Por esa motivo el movimiento Ni una Menos no fue sólo una alerta y un reclamo de medidas urgentes porque literalmente estaban asesinando a las mujeres, sino que fue (y es) una denuncia contra todo el orden social que tiene como denominador común la violencia y degradación de la mujer que exige un cambio inmediato y sustancial en todos los niveles.

Por ello se advierte que los femicidios son la consecuencia de todo un sistema que las menosprecia, relega y oprime. El presente trabajo busca poner de manifiesto cómo opera esa violencia en el campo laboral a través de la discriminación salarial, el acceso al empleo, las posibilidades de ascenso y la distribución de horas entre hombres y mujeres en el trabajo no remunerado (quehaceres domésticos, cuidado de hijos y/o parientes, etc.).

\section{Una aproximación a la problemática}

La preocupación internacional por la discriminación de género lleva varias décadas en agenda al punto que ya en la Constitución de la Organización Internacional del Trabajo (OIT) se establece en el preámbulo el "reconocimiento del principio del salario igual por un trabajo de igual valor" (concepto sobre el cual se ahondará más adelante). Claro que con el correr de los años se fue complejizando el análisis, explorando distintas aristas que hacen a la diferenciación entre hombres y mujeres en el plano laboral siendo en varios casos la brecha salarial una consecuencia de desigualdades previas. En un lenguaje coloquial, las distintas remuneraciones por motivos de género es sólo la punta del iceberg de un problema más profundo. 
En los primeros días de octubre se celebró la decimonovena Reunión Regional Americana de la OIT donde uno de los temas que se debatieron estuvo vinculado a los "avances y retos en reducir la brecha salarial y otras brechas de género en el marco de la Agenda 2030 para el Desarrollo Sostenible" . Esa sesión informativa fue acompañada por un informe que señala que "entender la desigualdad salarial pasa por analizar la segregación horizontal que confina a las mujeres a un número relativamente pequeño de ocupaciones concentradas en los sectores de menor productividad; y la segregación vertical, que dificulta su ascenso en la jerarquía de las empresas, relegándolas de esta manera a los trabajos peor pagados. Otros factores que impactan la remuneración que reciben las mujeres incluyen: la necesidad de combinar trabajo remunerado y no remunerado, la responsabilidad por el cuidado de las personas dependientes, las formas de violencia que limitan su participación y desempeño, y la discriminación ligada a su rol reproductivo".

El párrafo precedente resulta clarificador para comprender de qué se habla cuando se debate la discriminación laboral por razones de género. No se limita a la distinta remuneración que perciben un hombre y una mujer que realizan una misma tarea (que también existe), sino que va mucho más allá e implica estereotipos (a romper) sobre el rol de la mujer y el hombre en la sociedad en los cuales la primera está destinada a abocarse más a las tareas domésticas y la maternidad mientras que el segundo tiende a volcarse a su capacidad productiva, y sobre las labores que puede (o no) llevar adelante una mujer; y también la violencia de la que es víctima por su condición que está ampliamente extendida en el mundo del trabajo.

A modo de síntesis, utilizando una herramienta analítica y metodológica empleada por los organismos internacionales, se

\footnotetext{
1 La Asamblea General de Naciones Unidas adoptó el 25 de septiembre de 2015 la Agenda 2030 para el Desarrollo Sostenible, la cual contiene diecisiete objetivos a cumplir para esa fecha llamados objetivos de desarrollo sostenible (ODS).
} 
puede decir que existe una brecha salarial explicable cuando la peor remuneración que perciben las mujeres obedece a características observables como la educación, la experiencia laboral, el sector económico donde se desempeñan, la región, la intensidad laboral y la ocupación. Y una brecha salarial no explicada donde tiene una influencia determinante la discriminación directa.

\section{Estadísticas mundial, regional y de Argentina sobre la discriminación laboral}

Sin desagregar las cifras en la brecha salarial explicada y la no explicada, a nivel mundial las mujeres cobran un 23\% menos que los hombres. Según estadísticas de la Organización de Naciones Unidas (ONU), las mujeres ganan en promedio 77 centavos por cada dólar que perciben los hombres. Sin embargo, la situación no es homogénea entre los distintos países: en Costa Rica o Luxemburgo la brecha es menor al 5\% mientras que en Corea del Sur llega al 36\%, por mencionar polos extremos.

Esa situación se agrava con la edad, en particular cuando las mujeres tienen hijos. Se estima que con cada nacimiento, la mujer pierde promedio un $4 \%$ de su salario. La asesora de ONU Mujer, Anuradha Seth, advirtió que "buena parte del problema es el trabajo familiar no remunerado que las mujeres siguen llevando a cabo de forma desproporcionada".

Otra tendencia llamativa es que a mayor nivel de salarios (que por lo general va acompañado de un nivel más elevado de instrucción), más amplia es la brecha salarial. Tomando como ejemplo a Europa en el 2010, el 10\% de las trabajadoras en la parte más baja de la escala salarial ganaban 100 euros mensuales menos que el $10 \%$ de los hombres en la misma posición. Por el contrario, el 10\% de las mujeres que percibían salarios más altos ganaban 700 euros menos al mes que el 10\% de los hombres mejor remunerados ${ }^{2}$.

\footnotetext{
2 Oficina Internacional del Trabajo de la OIT, “Informe Mundial sobre Salarios 2014/2015: Salarios y desigualdad de ingresos", p. 55, Ginebra, 2015.
} 
Uno de los aspectos medulares de la brecha salarial explicada lo constituye el trabajo no remunerado. Los datos internacionales al respecto son contundentes: el 75\% del trabajo doméstico y de cuidados es realizado por mujeres. Ellas dedican 2,6 veces más tiempo al denominado trabajo no remunerado que los hombres. En promedio, las mujeres dedican un 18\% de su jornada a esa labor mientras que los hombres un $7 \%$. Esta diferenciación encuentra su sostén en estereotipos que se arraigan desde muy tempana edad. Un estudio de treinta y tres países realizado por la ONU Mujeres muestra que las niñas de entre siete y catorce años de edad realizan más tareas domésticas que los niños de la misma edad. ${ }^{3}$

En América Latina y el Caribe, si bien ha crecido la tasa de participación laboral de las mujeres, sigue habiendo una diferencia de $25 \%$ respecto a los hombres. En relación al desempleo, las tasas de las mujeres son más elevadas que la de los hombres $(10,4 \%$ frente a 7,6\%), agravándose la situación en el caso de las mujeres jóvenes que en 2016 tenían una tasa de desempleo del 22,2\% frente al 15,5\% de los hombres. En la región, los datos confirman la intensidad de la segregación horizontal: el 63\% de las mujeres se desempeña en los sectores de servicios sociales, comunales y personales, y de comercio, generalmente asociados a menores niveles educativos, bajos salarios, escasa cobertura de seguridad social, más inseguridad en el trabajo y ausencia de contrato.

En relación a la brecha salarial, según un relevamiento de 2015 en América Latina es del 15\%. Si se la subdivide geográficamente, se advierte que en el Cono Sur es del $21,4 \%$, en la Región Andina del 16\%, mientras que en Centroamérica y México es del 9,9\%. ${ }^{4}$

3 ONU Mujeres, "Hacer las promesas realidad: la igualdad de género en la agenda 2030 para el desarrollo sostenible", p. 94, Estados Unidos, 2018.

4 Oficina Regional de la OIT para América Latina y el Caribe, "Panorama Laboral 2017: América Latina y el Caribe", p. 76, Perú, 2017. 
La situación de la Argentina sigue las tendencias mundiales y propias de la región. En la publicación "Las mujeres ganan menos que los hombres en todo el planeta", las economistas Mercedes D'Alessandro ${ }^{5}$ y Magalí Brosio ${ }^{6}$ señalan que en Argentina las mujeres ganan en promedio $27,2 \%$ menos que los varones. Detallan, utilizando fuentes de la Organización Internacional del Trabajo (OIT), que el 46,3\% de esta diferencia se explica en características observables como la educación, la experiencia laboral, el sector económico, la región, la intensidad laboral y ocupación. Es decir, la brecha explicable obedece a que los empleos peor remunerados son mayoritariamente ocupados por mujeres (por ejemplo en Argentina, sólo el 7\% de los cargos ejecutivos -CEOS- en empresas están ocupados por mujeres), a que las mujeres dedican más tiempo a tareas domésticas obligándolas a abocarse menos horas al trabajo, etc. Ahora bien, el 53,7\% restante que constituye la brecha no explicada, no tiene una respuesta única pero sí existen datos e indicios que dan cuenta de que aún persiste una distinta remuneración por la realización de una misma tarea.

Esta primera aproximación sirve para dimensionar que todavía resta mucho camino por recorrer, y que no alcanza con lograr medidas efectivas que borren la discriminación salarial por igual tarea, porque aun teniendo éxito en ese punto, faltaría abordar la problemática de los factores que constituyen la brecha salarial explicada.

Ambas aristas de la problemática quedan muy bien evidenciadas en el informe sobre las "Mujeres en el mercado de trabajo argentino" publicado por el extinto Ministerio de Trabajo, Empleo y Seguridad Social de la Nación sobre estadísticas del tercer trimestre de $2017^{7}$. Allí se indicaba que la tasa de

\footnotetext{
5 Mercedes D’Alessandro es doctora en economía de la Universidad de Buenos Aires.

6 Magalí Brossio es licenciada en economía de la Universidad de Buenos Aires.

7 Dirección General de Estudios Macroeconómicos y Estadísticas Laborales, (ex) Ministerio de Trabajo, Empleo y Seguridad Social de la Nación, “Mujeres en el Mercado de Trabajo Argentino", Argentina, 2018.
} 
participación en actividades domésticas de las mujeres era del $88,9 \%$ mientras que la de los hombres, del 57,9\%. En promedio, las mujeres dedican 6,4 horas diarias a las tareas domésticas mientras que los varones 3,4 (un 90\% menos). Ello se traduce en que un $28,3 \%$ de las mujeres trabajan a tiempo completo en tareas remuneradas mientras que un $52,4 \%$ lo hace a tiempo parcial. En el caso de los hombres se invierte la ecuación: un $25,4 \%$ a tiempo parcial y un $38,2 \%$ a tiempo completo. Esto último tiene un correlato en los ingresos: el ingreso promedio mensual de los hombres era, a la fecha de medición, de \$15.588 mientras que el de las mujeres de \$11.644. La diferencia se explica en las horas que trabaja cada uno: mientras los hombres trabajaban semanalmente en promedio 43,4 horas, las mujeres lo hacían 32,3. El ingreso promedio por hora era prácticamente de paridad: $\$ 92,6$ los hombres y $\$ 93,9$ las mujeres, pero le brecha surgía por la imposibilidad de las últimas de trabajar más tiempo.

\begin{tabular}{|l|c|c|}
\hline & MUJERES & HOMBRES \\
\hline Participación en actividades domésticas & $88,9 \%$ & $57,9 \%$ \\
\hline $\begin{array}{l}\text { Promedio horas diarias a actividades } \\
\text { domésticas }\end{array}$ & 6,4 & 3,4 \\
\hline Trabajo a tiempo parcial & $52,4 \%$ & $25,4 \%$ \\
\hline Trabajo a tiempo completo & $28,3 \%$ & $38,2 \%$ \\
\hline Ingreso promedio mensual & $\$ 11.644$ & $\$ 15.588$ \\
\hline Promedio horas trabajadas semanalmente & 32,3 & 43,4 \\
\hline
\end{tabular}

Fuente: DGEMyEL - (ex) MTEySS, en base a datos de la EPH - INDEC.

No obstante lo anterior, si se desagrega el análisis en niveles educativos, se observa que a mayor grado de formación, aumenta la desigualdad salarial por género sin considerar las horas trabajadas. Así, para el universo de personas con nivel educativo bajo (secundaria incompleta), el ingreso horario promedio de los hombres era de $\$ 69,4$ y el de las mujeres, $\$ 72,7$. En el nivel medio (secundario completo, o terciario o universitario incompleto) de $\$ 90,9$ para los hombres y $\$ 82,2$ para las mujeres. 
Está brecha se agudiza en caso de nivel educativo alto (terciario o universitario completo): el ingreso horario promedio de los hombres era de $\$ 153$ y el de las mujeres $\$ 133,2$.

\begin{tabular}{|c|c|c|c|c|c|c|}
\hline & \multicolumn{3}{|c|}{ MUJERES } & \multicolumn{3}{c|}{ HOMBRES } \\
\hline $\begin{array}{c}\text { Nivel } \\
\text { Educativo }\end{array}$ & $\begin{array}{c}\text { Ingreso } \\
\text { promedio } \\
\text { mensual }\end{array}$ & $\begin{array}{c}\text { Horas de } \\
\text { trabajo } \\
\text { semanales }\end{array}$ & $\begin{array}{c}\text { Ingreso } \\
\text { horario } \\
\text { promedio }\end{array}$ & $\begin{array}{c}\text { Ingreso } \\
\text { promedio } \\
\text { mensual }\end{array}$ & $\begin{array}{c}\text { Horas de } \\
\text { trabajo } \\
\text { semanales }\end{array}$ & $\begin{array}{c}\text { Ingreso } \\
\text { horario } \\
\text { promedio }\end{array}$ \\
\hline BAJ0 & $\$ 7.075$ & 30,8 & $\$ 72,7$ & $\$ 12.066$ & 43,7 & 69,4 \\
\hline MEDIO & $\$ 10.887$ & 35,2 & $\$ 82,2$ & $\$ 15.498$ & 45,3 & 90,9 \\
\hline ALTO & $\$ 17.026$ & 29,4 & $\$ 133,2$ & $\$ 24.464$ & 38,2 & 153,0 \\
\hline
\end{tabular}

Fuente: DGEMyEL - (ex) MTEySS, en base a datos de la EPH - INDEC.

Las cifras mencionadas, además de ilustrar lo exiguos que son los salarios en la República Argentina, no dejan lugar a dudas de que existe una grave problemática de discriminación por motivos de género, tanto por lo que se llama brecha explicada como por la denominada no explicada, evidenciada esta última sobre todo en el estrato de alto nivel educativo.

Los datos del Instituto Nacional de Estadísticas y Censos (INDEC) correspondientes al segundo trimestre de $2018^{8}$ reflejan que la mujer está en una situación desventajosa en relación al hombre, en sintonía con los patrones internacionales. La tasa de actividad femenina es del 48,5\% mientras que la masculina es del 69,5\%. En relación al desempleo, en las mujeres llega al 10,8\% y en los hombres al 8,7\%. Aquí también se agudiza esta diferencia en el caso de la juventud (de catorce a veintinueve años) donde la brecha es más intensa: en este rango, el desempleo femenino trepa al 21,5\% mientras que el masculino lo hace al 17,3\%

En los poderes del Estado, en vez de predicar con el ejemplo, se continúa la corriente de que los hombres ocupen en forma mayoritaria los lugares de toma de decisiones. No tanto en los poderes legislativos donde existen leyes de cupo

8 Instituto Nacional de Estadísticas y Censos, Ministerio de Hacienda de la Nación, “Mercado de Trabajo. Tasas e indicadores socioeconómicos (EPH) - segundo trimestre 2018", Buenos Aires, septiembre de 2018. 
femenino, fuesen de paridad total o bien de garantizar un 33\% de mujeres. En el gabinete nacional, previo a la reducción sufrida semanas atrás, de los veinte ministerios sólo dos eran conducidos por mujeres. La brecha se redujo al reducir a diez los ministerios quedando ocho en manos de hombres y dos en cabeza de mujeres. Sumando a todas las provincias y la Ciudad Autónoma de Buenos Aires, hay doscientos cuarenta y seis (246) ministerios. Ciento noventa y siete (197) están a cargo de hombres y cuarenta y nueve (49) de mujeres. Es decir, un $80 \%$ de los ministerios provinciales tienen a varones como Ministros y sólo un $20 \%$ a mujeres. En lo que respecta a los principales cargos electivos de Poderes Ejecutivos, incluyendo al Jefe de Estado, hay veintiuno en conducidos por hombres y sólo cuatro por mujeres.

Haciendo un repaso por el Poder Judicial, en la Corte Suprema de Justicia, de cinco miembros sólo una es mujer y el traspaso de presidencia realizado fue de un hombre para con otro hombre. Tomando un fuero que tiene amplia repercusión mediática en los últimos tiempos como el criminal y correccional federal, de los doce juzgados, diez están en manos de hombres y sólo uno en cabeza de una mujer (está vacante el juzgado que estaba a cargo de Norberto Oyarbide aunque es subrogado por un varón). En la Cámara Nacional de Apelaciones en lo Criminal y Correccional Federal no hay mujeres, y en la Cámara Federal de Casación Penal existe un claro predominio de varones.

\section{El marco normativo actual}

En Argentina, la ley de contrato de trabajo y la ley antidiscriminación disponen reglas claras. De esta manera, sobre el tema que compete a este texto, la primera prohíbe cualquier discriminación en el ámbito laboral por motivos de sexo, y se afirma el principio de "igual retribución por trabajo de igual valor" para las convenciones colectivas. La segunda dispone que quien ejerza un acto discriminatorio debe, a pedido del damnificado, dejarlo sin efecto o cesar en su realización. 
La Constitución Nacional en su artículo 14 bis indica que habrá "igual remuneración por igual tarea" y el artículo 15 enfatiza que "todos sus habitantes son iguales ante la ley, y admisibles en los empleos sin otra condición que la idoneidad".

Por último, cabe mencionar dos convenios fundamentales de la OIT a los que Argentina adhirió y que tienen jerarquía supralegal: el convenio 100 sobre igualdad de remuneración y el 111 sobre discriminación. El primero indica que todo Estado Miembro debe promover métodos para garantizar el principio de igualdad de remuneración entre la mano de obra masculina y la mano de obra femenina por un trabajo de igual valor entendiendo que esta expresión refiere a "tasas de remuneración fijadas sin discriminación en cuanto al sexo" (esta aclaración medular que el propio convenio hace será abordada más adelante). El convenio 111 obliga a los Estados Miembros a implementar políticas activas para eliminar todo tipo de discriminación que altere o anule la igualdad de oportunidades o de trato en el empleo u ocupación, incluyendo en esta definición tanto el acceso a los medios de formación profesional, la admisión en el empleo y las condiciones de trabajo ${ }^{10}$.

Hasta aquí es fácil observar que existe sobrada legislación para prohibir que dos personas que realizan la misma tarea cobren un salario distinto por motivo de su sexo. Falta una política más activa del Poder Ejecutivo Nacional (en colaboración con los ejecutivos provinciales) para fiscalizar y controlar el efectivo cumplimiento de estas disposiciones, y la consolidación de un mecanismo para que las víctimas de esta discriminación puedan acudir a las instancias estatales para que se respeten sus derechos sin que ello ponga en riesgo su situación laboral.

Sin embargo, cabe detenerse en un aspecto intrínseco. Una de las causas de la llamada brecha explicada reside en que las mujeres tienen dificultad para acceder a los trabajos mejor

9 Convenio No 100 OIT sobre igualdad de remuneración, 1951. Artículo 1 inciso b.

10 Convenio № 111 OIT sobre la discriminación (empleo y ocupación), 1958. Artículo 1. 
remunerados y, en cambio, hay predominancia femenina en los sectores de peores salarios. En ese sentido, en el Estudio General sobre los Convenios Fundamentales realizado en 2012, la OIT reiteró que "debido a actitudes históricas y los estereotipos relativos a las aspiraciones, preferencias y capacidades de las mujeres, ciertos trabajos son realizados fundamental o exclusivamente por mujeres y otros por hombres. Con frecuencia, los trabajos considerados como "femeninos" están infravalorados en comparación con los trabajos de igual valor desempeñados por los hombres, cuando se determinan las tasas salariales (...) La segregación laboral por motivos de sexo en el mercado de trabajo un problema que afecta a casi todos los países"11.

Existen mecanismos para moderar la preponderancia de esta problemática -que es de orden mundial y a la cual la Argentina no es ajena- en lo que respecta a la brecha salarial, sin perjuicio de que el objetivo siempre debe ser que la segregación laboral sea cosa del pasado.

Cabe retomar en este punto lo que dice el Convenio 100: "la expresión igualdad de remuneración entre la mano de obra masculina y la mano de obra femenina por un trabajo de igual valor designa las tasas de remuneración fijadas sin discriminación en cuanto al sexo". Esto implica que bajo este concepto no se cobija exclusivamente a dos personas que realizan la misma tarea, sino tareas de igual valor. La diferencia es sustancial. No cabe duda, por ejemplo, que un hombre y una mujer que son cajeros en un supermercado deben cobrar el mismo salario básico (podrá haber diferencias por antigüedad, si uno realizó horas extras y el otro no, etc.). ¿Pero qué significa tareas de igual valor? La Comisión de Expertos en Aplicación de Convenios y Recomendaciones (CEACR) de la OIT precisa que "el concepto de "igual valor" requiere un método de medición y

11 Comisión de Expertos en Aplicación de Convenios y Recomendaciones, OIT, “Estudio General sobre los convenios fundamentales relativos a los derechos en el trabajo a la luz de la Declaración de la OIT sobre la justicia social para una globalización equitativa", párrafo 673 , p. 300, 2012. 
comparación del valor relativo de los distintos empleos. Se debe proceder a un examen de las respectivas tareas cumplidas, que se llevará a cabo sobre la base de criterios absolutamente objetivos y no discriminatorios para evitar que la evaluación se vea condicionada por los prejuicios de género. Si bien en el Convenio no se establece ningún método específico para ese examen, en el artículo 3 se presupone el uso de técnicas adecuadas para la evaluación objetiva del empleo con miras a determinar su valor, mediante la comparación de factores tales como las calificaciones, el esfuerzo, las responsabilidades y las condiciones de trabajo". Agrega que "la aplicación del principio consagrado en el Convenio no se limita a la comparación entre los hombres $y$ las mujeres en un mismo establecimiento o empresa, sino que permite una comparación mucho más amplia entre los empleos desempeñados por los hombres y las mujeres en distintos lugares o empresas, o entre distintos empleadores ${ }^{12 " . ~}$

En el informe que acompaño el debate sobre los "Avances y retos en reducir la brecha salarial y otras brechas de género en el marco de la Agenda 2030 para el Desarrollo Sostenible" en la Reunión Regional Americana de la OIT se reiteró el alcance que la CEACR le dio a la expresión "igual salario por tareas de igual valor" y enfatizó que esta idea "refiere a la necesidad de revalorizar social y monetariamente las ocupaciones realizadas por mujeres, muchas de ellas ligadas al rol tradicional que han desempeñado históricamente en los hogares sin ninguna remuneración. Entender la desigualdad salarial pasa por analizar la segregación borizontal que confina a las mujeres a un número relativamente pequeño de ocupaciones concentradas en los sectores de menor productividad; y la segregación vertical, que dificulta su ascenso en la jerarquía de las empresas, relegándolas de esta manera a los trabajos peor pagados".

12 Comisión de Expertos en Aplicación de Convenios y Recomendaciones, OIT, "Estudio General sobre los convenios fundamentales relativos a los derechos en el trabajo a la luz de la Declaración de la OIT sobre la justicia social para una globalización equitativa", párrafo 695, p. 310, 2012. 
Esto significa que aunque el objetivo de máxima sería eliminar la segregación laboral, mientras exista debe haber mecanismos para evitar la brecha salarial. De forma tal que el Convenio 100 insta a asignarles a los distintos empleos un valor en función de criterios objetivos, y que todos los trabajos de igual valor tengan una misma remuneración.

\section{Alternativas a futuro}

Como se advirtiera al inicio, la brecha salarial en numerosas oportunidades es producto de una serie de discriminaciones y dificultades precedentes. Los debates y esfuerzos a escala internacional buscan poner en evidencia y desarticular esta desigualdad estructural, por lo que los análisis no se limitan a la participación de las mujeres en el mercado laboral y una comparación nominal de salarios, sino que van más allá poniendo sobre el tablero la incidencia de las tareas domésticas no remuneradas, la maternidad, y la construcción de estereotipos ligados al rol que históricamente se le asignó a la mujer en la sociedad. Tal es así que en el ODS número cinco sobre igualdad de género, las metas 5.4 y 5.5 establecen que es necesario "reconocer $y$ valorar los cuidados y el trabajo doméstico no remunerados mediante servicios públicos, infraestructuras y políticas de protección social, y promoviendo la responsabilidad compartida en el bogar y la familia, según proceda en cada país" y "asegurar la participación plena y efectiva de las mujeres, y la igualdad de oportunidades de liderazgo a todos los niveles decisorios en la vida política, económica y pública", respectivamente. Las cuales están vinculadas con el ODS número ocho sobre trabajo decente y crecimiento económico, que en su meta 8.5 establece la necesidad de lograr en el 2030 "el empleo pleno y productivo y el trabajo decente para todas las mujeres y los hombres, incluidos los jóvenes y las personas con discapacidad, así como la igualdad de remuneración por trabajo de igual valor". En el mismo sentido, la Reunión Regional Americana culminó con la publicación de la Declaración de Panamá "por el futuro 
del trabajo en las Américas". Allí, en el capítulo sobre "¿cómo construir un mejor futuro de trabajo?", señala en el punto XVI que, entre otras medidas, se logra con "politicas para promover la igualdad de género y la no-discriminación en los mercados de trabajo, incluyendo medidas para combatir los estereotipos de género; para incentivar la aplicación del principio de igual salario por trabajo de igual valor; para una mayor valorización y reconocimiento del trabajo del cuidado; y para prevenir y combatir la violencia y el acoso en el mundo del trabajo".

Teniendo en cuenta las múltiples dimensiones de la problemática, lo primero que se necesita es tener un diagnóstico claro para saber hacia dónde direccionar las políticas públicas. Ergo, es indispensable mejorar y perfeccionar la metodología para obtener estadísticas. A la información que ya brinda la Encuesta Permanente de Hogares de forma trimestral sobre empleo, desempleo, actividad, subocupación, etc., y características como el rango etario, nivel de instrucción, sector de actividad, si está en el circuito formal o informal, se debe agregar una recolección periódica sobre remuneración percibida, horas trabajadas, horas dedicadas a tareas domésticas no remuneradas, lugar de residencia, condiciones de la misma, circunstancias socioeconómicas, etc. Disponer de tal detalle de información permite entrecruzar datos y descubrir casos de reiteración de patrones para luego implementar distintos tipos de medidas. Verbigracia, en áreas donde la población no tiene acceso a la red de agua potable, una primera política indispensable sería la de generar esa conectividad que además de satisfacer un derecho esencial, permitiría reducir el tiempo que demandan ciertas tareas domésticas. No está de más reiterar que esto de ninguna manera implica aceptar, compartir, naturalizar o justificar el desigual reparto de horas dedicadas a las actividades no remuneradas que existen entre hombres y mujeres, pero no se puede desconocer la realidad y se deben buscar medios en distintas instancias para revertir esta situación.

También podría ser de utilidad contar con un monitoreo sobre la composición de la nómina de empleados de empresas 
radicadas en Argentina, y la distribución de tareas, jerarquías, salarios y bonos en función del género. A su vez sería interesante disponer de información estadística que refleje, en términos proporcionales, qué género se ve más afectado cuando las empresas llevan adelante una reestructuración, reducción de personal o suspensiones. Y en épocas expansivas donde toman nuevos empleados, cuál es la proporción de hombres y mujeres que se entrevistan como aquellos que efectivamente se contratan.

Información detallada y regular permitirá obtener un panorama bastante más certero de la actualidad. A partir de allí, habrá que instrumentar medidas para atender cada uno de los orígenes de la desigualdad. Los casos de la brecha no explicada que están mayoritariamente ligados a discriminaciones directas, es decir, a que una mujer cobre menos que un hombre cuando hace exactamente la misma tarea, encuentra abundantes herramientas en la legislación para combatirlo. Este tipo de situaciones son más comunes en el sector informal de la economía donde hay menos controles y, obviamente, menos apego a la ley. En el sector formal quizá es más probable hallar situaciones de discriminación oculta detrás de la adjudicación de determinadas bonificaciones o plus salariales. En ambos casos, siendo el ordenamiento jurídico lo suficientemente claro, se requiere reforzar la capacidad fiscalizadora del Estado y establecer penalidades más severas ante incumplimientos. A esto podría sumarse la importancia de capacitar a los agentes del Estado en materia de género. Costa Rica desarrolló una guía para la Inspección del Trabajo con Enfoque de Género de forma tal de facilitar la tarea de los inspectores a la hora de identificar infracciones en materia de igualdad salarial.

Luego está el amplio abanico de la llamada brecha explicada, donde la brecha salarial es producida por una gran variedad de causas muchas veces relacionadas e influenciadas entre sí. Aquí juegan los estereotipos que ven que las mujeres no pueden desarrollar ciertos trabajos o no están capacitadas para hacerlo, la menor disponibilidad para trabajar por dedicarse a tareas 
domésticas no remuneradas, la decisión de no contratar o promocionar mujeres por la posibilidad futura de que hagan uso de licencias pagas o el prejuicio de que incumplan sus tareas por atender asuntos familiares, por mencionar algunas. El desafío está en implementar medidas que amortigüen los efectos de la segregación horizontal y vertical, y también que busquen combatirlas, en sintonía con los postulados y propuestas de organismos internacionales como la OIT o la ONU Mujeres que junto a la OCDE, lideran la Coalición Internacional sobre la Igualdad de Remuneración ${ }^{13}$.

En primer lugar, habría que darle operatividad al mandato de la OIT de igual remuneración por tareas de igual valor con los alcances explicados anteriormente. Esto no elimina la segregación horizontal, pero mitiga la brecha salarial que ella provoca al cuantificar cada trabajo en función de criterios objetivos, y atar las remuneraciones al valor de cada empleo. En la Reunión Regional Americana se citó el caso de Chile que llevó adelante una experiencia piloto para visibilizar la brecha salarial de género a la luz de la máxima de la OIT en el Instituto de Seguridad Laboral. Se explicó que este estudio piloto permitió analizar todos los puestos de trabajo de dicho instituto y la relación salarial mediante la aplicación de una metodología para calcular el valor de cada puesto, y determinar los salarios adecuadamente. Más allá de garantizar la igualdad salarial, esta experiencia permitirá seguir reorientando esfuerzos similares en otras instituciones y empresas. Bélgica y los Países Bajos han puesto en marcha institutos de clasificación de los trabajos para dar cumplimiento a la igual remuneración por tareas de igual valor.

Otra política de estado podría vincularse a un aumento significativo del salario mínimo, vital y móvil. Las actividades peor

\footnotetext{
13 La EPIC (Equal Pay International Coalition) fue oficialmente lanzada en septiembre de 2017 durante la asamblea general de las Naciones Unidas en Nueva York. Consiste en una alianza de múltiples partes interesadas con miras a contribuir a la consecución de la Meta 8.5 de los ODS, el cual se centra en la igualdad de remuneración entre mujeres y hombres por un trabajo de igual valor.
} 
remuneradas son ocupadas mayoritariamente por mujeres. Un aumento considerable del salario mínimo (que hoy se encuentra en $\$ 10.700$ y se elevará a $\$ 12.500$ en junio de 2019 , muy por debajo de lo necesario para cubrir las necesidades básicas) sería otra manera de contribuir a reducir la brecha salarial existente. Bulgaria y el Reino Unido han tenido resultados positivos con este tipo de políticas. Según un informe de la Low Pay Commission del Reino Unido ${ }^{14}$, el aumento del salario mínimo en 2008 tuvo un impacto mayor en puestos de trabajo ocupados preponderantemente por mujeres.

Sin perjuicio de lo anterior, también hay iniciativas que pueden adoptarse para quebrar el proceso de segregación horizontal y vertical. Una política de cupos ha demostrado ser efectiva para esta finalidad. España y Noruega son testigos de ellos. Podría imponerse su obligatoriedad o bien incentivar a las compañías a través de beneficios impositivos a adherirse a ella. Un sector de la doctrina podría rechazar la imposición de tal medida en virtud de la libertad de contratar que surge del derecho a ejercer industria lícita del artículo 14 de la Constitución Nacional. Esa pretensión ya ha sido ampliamente desestimada por la justicia. En "Freddo"15, leading case en materia de discriminación laboral contra las mujeres, la Cámara Nacional en lo Civil sostuvo que "si bien es cierto que la Constitución Nacional garantiza la libertad de contratar, también lo es que los derechos que reconoce la Constitución Nacional no son absolutos sino que están sujetos a las leyes que los reglamenten. A su vez, la probibición de discriminar constituye un limite a dicha libertad, lo que obliga al empleador a utilizar un criterio neutro predicable por igual para el bombre y la mujer -en el caso de las discriminaciones directas-, así como a rechazar aquellos otros criterios que, aun cuando sean formalmente neutros, produzcan un resultado adverso para los integrantes de uno y otro sexo, en el

\footnotetext{
14 La Comisión de Bajos Salarios es un organismo independiente que asesora al gobierno del Reino Unido sobre el salario vital nacional y el salario mínimo nacional.

15 “Fundación Mujeres en Igualdad y otro c/Freddo SA s/amparo", Sala H de la Cámara Nacional en lo Civil, 16 de diciembre de 2002.
} 
supuesto de las denominadas discriminaciones indirectas o de impacto adverso". Aunque frente a supuestos fácticos distintos, en el caso "Cencosud"16, el voto mayoritario de la Corte Suprema ratificó el concepto de que "la Constitución Nacional debe ser entendida como una unidad, esto es, como un cuerpo que no puede dividirse sin que su esencia se destruya o altere, como un conjunto armónico en el que cada uno de sus preceptos ha de interpretarse de acuerdo con el contenido de los demás" para condicionar el derecho a contratar al respeto de los derechos consagrados en los instrumentos internacionales de derechos humanos que integran el bloque de constitucionalidad.

Existen dos fenómenos asociados a la segregación laboral conocidos bajo los eufemismos de suelo pegajoso y techo de cristal. El primero refiere a las circunstancias que mantienen a numerosas mujeres atrapadas en la base de la pirámide económica, abocadas al trabajo maternal, conyugal y doméstico. El segundo alude a una barrera invisible (pero no por ello irreal) a partir de la cual numerosas mujeres se ven imposibilitadas de ascender en su carrera laboral y, por tanto, viéndose impedidas de acceder a lugares de jerarquía. Hay distintos tipos de instrumentos que permiten remover esos obstáculos, minimizando las motivaciones económicas que desalientan a los empleadores a contratar o ascender mujeres en edad fértil o con hijos a cargo, y que facilitan las condiciones para que las mujeres (y hombres) puedan afrontar sus compromisos laborales sin verse en la necesidad de elegir entre el trabajo y sus obligaciones no remuneradas.

Una de ellos es el régimen de licencias. Podría equipararse la licencia por paternidad a la de maternidad, y establecer una posterior licencia parental a ser usada por cualquiera de los dos progenitores a elección en el seno de la pareja. De esta manera, el argumento (insensiblemente) económico de no contratar o promover a una mujer para, eventualmente, no tener que

\footnotetext{
16 "Álvarez, Maximiliano y otros c/Cencosud S.A. s/ acción de amparo", Corte Suprema de Justicia de la Nación, 7 de diciembre de 2010.
} 
concederle una licencia paga quedaría desarticulado. Además, ya no sería la ley la que impone cuál de los dos progenitores debe quedarse al cuidado del recién nacido en sus primeras semanas de vida. Cabe recordar, a su vez, que la OIT recomienda una licencia por maternidad mínima de dieciocho semanas, encontrándose Argentina por debajo de ese umbral.

El cuidado y atención de los hijos menores no se agota en sus primeras semanas de vida. A ello hay que sumarle que en muchas ocasiones los trabajadores deben ocuparse de otros familiares (en general adultos mayores) que requieren asistencia, recayendo esa tarea también en las mujeres. Esto fue y es motivo de preocupación por la OIT y promovió la sanción del convenio $\mathrm{N}^{\circ} 156$ sobre trabajadores con responsabilidades familiares y su respectiva Recomendación $\mathrm{N}^{\circ} 165$. Si bien no contiene disposiciones concretas, insta a los Estados a adoptar medidas que permitan a los trabajadores con responsabilidades familiares conciliar sus responsabilidades profesionales $\mathrm{y}$ familiares. Para atender esta situación, podría haber una fuerte inversión en centros de atención y educación de la primera infancia accesibles, públicos y de calidad, como también en centros de día o residenciales para personas mayores. También se podría establecer un régimen de licencia paga por atención de familiares a cargo, implementar sistemas de flexibilidad laboral para compatibilizar las responsabilidades laborales con las extra laborales, o promocionar, en los empleos donde sea posible, la modalidad de teletrabajo o home office.

En atención a lo vertido en los párrafos anteriores, sería saludable que gobierno, organizaciones de trabajadores $y$ asociaciones de empresarios trabajen mancomunadamente en protocolos y guías de actuación a los cuales deberían apegarse los empleadores a la hora de llamar a concursos y realizar entrevistas para contratar o ascender personal. De forma que la decisión final esté sostenida únicamente en criterios objetivos excluyendo cualquier apreciación subjetiva al respecto.

Argentina ha dado algunos pasos en los últimos años con la implementación de la Asignación Universal por Hijo y la 
Asignación Universal por Embarazo, la ley de trabajadoras de casas particulares o las moratorias jubilatorias que beneficiaron principalmente a mujeres. Sin embargo queda mucho camino por recorrer y estereotipos que desarmar. No basta con modificar algunos artículos de la ley de contrato de trabajo, sino que debe haber una fuerte política de estado por una real igualdad que abarque programas de capacitación y deconstrucción en la sociedad, un activo rol del Poder Ejecutivo, una mejora de la legislación vigente por parte del Congreso, y que en la esfera de los tres poderes del Estado como en el ámbito de negociación colectiva que incluye a las organizaciones de trabajadores y empleadores, todas las decisiones que se tomen hayan tenido un previo estudio con perspectiva de género, entendiendo por tal al proceso consistente en evaluar las implicaciones que para mujeres y hombres tienen las iniciativas planificadas, ya sea en forma de legislación, políticas o programas, en cualquier ámbito y en todos los planos. Es una estrategia que permite integrar las preocupaciones y las experiencias tanto de mujeres como de hombres en la concepción, la aplicación, el seguimiento y la evaluación de políticas y programas en las esferas política, económica y social, de suerte que las mujeres y los hombres se beneficien por igual de los progresos y no se perpetúe la desigualdad. El fin último que se persigue con esta integración es lograr la igualdad de género ${ }^{17}$.

17 Según la definición del Consejo Económico y Social de las Naciones Unidas, julio de 1997. 